\title{
Mitochondrial Inhibitor Models of Huntington's Disease and Parkinson's Disease Induce Zinc Accumulation and Are Attenuated by Inhibition of Zinc Neurotoxicity in vitro or in vivo
}

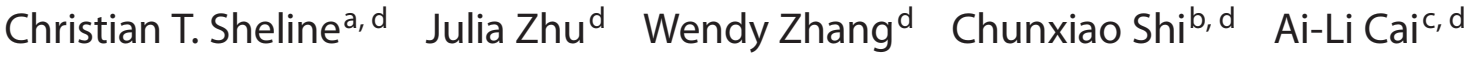 \\ ${ }^{a}$ Department of Ophthalmology and the Neuroscience Center of Excellence, Louisiana State University Health \\ Sciences Center, New Orleans, La., and Departments of b Surgery, ' Biomedical Engineering and d Neurology, \\ Washington University, Saint Louis, Mo., USA
}

\section{Key Words}

3-Nitropropionic acid $\cdot$ 6-Hydroxydopamine .

$\mathrm{N}$-methyl-4-phenylpyridium $\cdot$ Zinc neurotoxicity ·

Glycolytic inhibition

\begin{abstract}
Background: Inhibition of mitochondrial function occurs in many neurodegenerative diseases, and inhibitors of mitochondrial complexes I and II are used to model them. The complex II inhibitor, 3-nitroproprionic acid (3-NPA), kills the striatal neurons susceptible in Huntington's disease. The complex I inhibitor N-methyl-4-phenylpyridium $\left(\mathrm{MPP}^{+}\right)$and 6-hydroxydopamine (6-OHDA) are used to model Parkinson's disease. Zinc $\left(\mathrm{Zn}^{2+)}\right.$ accumulates after 3-NPA, 6-OHDA and $\mathrm{MPP}^{+}$in situ or in vivo. Objective: We will investigate the role of $\mathrm{Zn}^{2+}$ neurotoxicity in 3-NPA, 6-OHDA and MPP'. Methods: Murine striatal/midbrain tyrosine hydroxylase positive, or near-pure cortical neuronal cultures, or animals were exposed to 3-NPA or $\mathrm{MPP}^{+}$and 6-OHDA with or without neuroprotective compounds. Intracellular zinc $\left(\left[\mathrm{Zn}^{2+}\right]_{\mathrm{i}}\right)$, nicotinamide adenine dinucleotide $\left(\mathrm{NAD}^{+}\right), \mathrm{NADH}$, glycolytic intermediates and neurotoxicity were measured. Results: We showed that compounds or genetics which restore $N A D^{+}$ and attenuate $\mathrm{Zn}^{2+}$ neurotoxicity (pyruvate, nicotinamide, $\mathrm{NAD}^{+}$, increased $\mathrm{NAD}^{+}$synthesis, sirtuin inhibition or $\mathrm{Zn}^{2+}$
\end{abstract}

chelation) attenuated the neuronal death induced by these toxins. The increase in $\left[\mathrm{Zn}^{2+}\right]_{i}$ preceded a reduction in the $\mathrm{NAD}^{+} / \mathrm{NADH}$ ratio that caused a reversible glycolytic inhibition. Pyruvate, nicotinamide and $\mathrm{NAD}^{+}$reversed the reductions in the $\mathrm{NAD}^{+} / \mathrm{NADH}$ ratio, glycolysis and neuronal death after challenge with 3-NPA, 6-OHDA or $\mathrm{MPP}^{+}$, as was previously shown for exogenous $\mathrm{Zn}^{2+}$. To test efficacy in vivo, we injected 3-NPA into the striatum of rats and systemically into mice, with or without pyruvate. We observed early striatal $\mathrm{Zn}^{2+}$ fluorescence, and pyruvate significantly attenuated the 3-NPA-induced lesion and restored behavioral scores. Conclusions: Together, these studies suggest that $\mathrm{Zn}^{2+}$ accumulation caused by $\mathrm{MPP}^{+}$and 3-NPA is a novel preventable mechanism of the resultant neurotoxicity.

Copyright $\odot 2012$ S. Karger AG, Basel

\section{Introduction}

An impairment of energy metabolism underlies neuronal death in neurodegenerative diseases (reviewed in [1]). Huntington's disease (HD) is a progressive neurodegenera-

J.Z. and W.Z contributed equally to this work.

An abstract of this study has been presented at the Society for Neurosciences in 2003, New Orleans, La., USA

\section{KARGER}

Fax +4161306 1234

E-Mail karger@karger.ch

www.karger.com (c) 2012 S. Karger AG, Basel

1660-2854/13/0111-0049\$38.00/0

Accessible online at:

www.karger.com/ndd
Christian T. Sheline

LSUHSC, Neuroscience Center of Excellence

2020 Gravier St., Suite D

New Orleans, LA 70112 (USA)

Tel. +1 504599 0880, E-Mail csheli@lsuhsc.edu 
tive disorder characterized by chorea, psychiatric disturbances and dementia. The striatum is the primary site of neuronal loss in HD. The mechanism of neurodegeneration and the underlying cause of the selectivity for the striatum are thought to involve inhibition of mitochondrial electron transport at complex II and the selective vulnerability of the striatum to energy impairment $[2,3]$. Chronic systemic injection of 3-nitropropionic acid (3-NPA, complex II inhibitor) into mice or rats induces bilateral striatal lesions with many neuropathological features of $\mathrm{HD}$ and, therefore, is widely used as a model of $\operatorname{HD}[4,5]$. Reactive oxygen species (ROS) have been suggested to play a substantial role in the neurotoxicity of 3-NPA-induced neuronal injury; effective antioxidants partially attenuate (up to 50\%) 3-NPA lesions [6, 7]. These radicals cause intracellular and extracellular $\mathrm{Zn}^{2+}$ accumulation in slices exposed to 3-NPA as determined by $\mathrm{Zn}^{2+}$ fluorescence [8]

Oxidative stress is also thought to contribute to dopaminergic cell death in Parkinson's disease (PD) as evidenced by biochemical changes occurring in the substantia nigra (such as increased iron levels, inhibition of complex I activity and decreased glutathione levels) $[9,10]$. The catecholaminergic neurotoxin 6-hydroxydopamine (6-OHDA) has been shown to form endogenously in patients suffering from PD and its injection is used as an animal model of PD [11, 12].

The involvement of ROS in N-methyl-4-phenylpyridinium $\left(\mathrm{MPP}^{+}\right)$toxicity of dopamine-secreting neurons is unclear. Free-radical-sensitive fluorophores, as well as measurements of lipid peroxidation and vital dyes, were used to demonstrate increased production of ROS in dopaminergic neurons treated with 6-OHDA compared to $\mathrm{MPP}^{+}[13,14]$. 1-Methyl-4-phenyl-1,2,3,6-tetrahydropyridine (MPTP) is the precursor to $\mathrm{MPP}^{+}$, and both have been shown to induce $\mathrm{Zn}^{2+}$ release and an increase in intracellular zinc $\left(\left[\mathrm{Zn}^{2+}\right]_{\mathrm{i}}\right)$ in degenerating striatal neurons in vivo and in situ $[15,16]$. We recently showed that ROS induces an increase in $\left[\mathrm{Zn}^{2+}\right]_{i}$ and a loss of nicotinamide adenine dinucleotide $\left(\mathrm{NAD}^{+}\right)$, causing inhibition of glycolysis and neuronal death; accordingly, preventing this increase or loss prevents this outcome [17].

In this study, we investigated the role of $\mathrm{Zn}^{2+}$ neurotoxicity in 3 neurotoxins (3-NPA, 6-OHDA and $\mathrm{MPP}^{+}$) commonly used as models for HD and PD. We examined $\left[\mathrm{Zn}^{2+}\right]_{\mathrm{i}}, \mathrm{NAD}^{+} / \mathrm{NADH}$ levels, glycolytic inhibition and the efficacy of compounds and genotypes, which restore $\mathrm{NAD}^{+}$or reduce $\mathrm{Zn}^{2+}$ levels, to attenuate mitochondrial inhibition-mediated injury in vitro, and against 3-NPA injections in vivo. These compounds and genotypes were used due to their efficacy against $\mathrm{Zn}^{2+}$ neurotoxicity.

\section{Experimental Procedures}

\section{Cell Culture and Toxicity Studies}

Near-pure cortical neuronal cell cultures were prepared from E15 Swiss-Webster, C57/B16J, ZnT3-/-, MT3-/-, or Wallerian degeneration-slow $\left(\mathrm{Wld}^{\mathrm{s}}\right)$ mice as previously described [18]. Cultures from striatum/midbrain of Swiss-Webster mice were prepared likewise (except at 12 hemispheres/plate), and the growth of glia was inhibited by feeding with Neurobasal medium A + B27 after 3 days [19].

Slow toxicity was initiated after 8 days in vitro, by exposure to $100-1,000 \mu \mathrm{M} 3-\mathrm{NPA}, 50-200 \mu \mathrm{M}$ 6-OHDA or 5-400 $\mu \mathrm{M}$ $\mathrm{MPP}^{+}$in MEM-defined media $+26 \mathrm{mM}$ sodium bicarbonate and $21 \mathrm{mM}$ glucose $+1 \mu \mathrm{M}$ MK-801 and $50 \mathrm{ng} / \mathrm{ml}$ of brain-derived neurotrophic factor (BDNF, Cellsciences, Canton, Mass., USA). Due to the lack of glia, BDNF was included to prevent trophic deprivation, and MK-801 was included to prevent wash-induced glutamate release and excitotoxicity in near-pure neuronal cultures. The efficacy of pyruvate, lactate, thiamine or nicotinamide $(10 \mathrm{mM}), 6 \mathrm{~mm} \mathrm{NAD}{ }^{+}, 10 \mu \mathrm{M}$ sirtinol or $10 \mu \mathrm{M} \mathrm{N}, \mathrm{N}^{\prime} \mathrm{N}^{\prime} \mathrm{N}^{\prime}-$ tetrakis(2-pyridylmethyl) ethylenediamine (TPEN, specific $\left[\mathrm{Zn}^{2+}\right]_{\mathrm{i}}$ chelator) were tested after dose-finding experiments determined these concentrations to maximally reduce toxicities. Cell death was assayed $24-48 \mathrm{~h}$ later by lactate dehydrogenase efflux to the bathing medium, or by staining with 3-(4,5-dimethylthiazol-2-Yl)-2,5-diphenyltetrazolium bromide (MTT) or by staining with propidium iodide (PI), with an $n=9-12$ for each condition [20]. Toxicity mediated by 3-NPA takes more time to occur than $\mathrm{MPP}^{+}$or 6-OHDA toxicities (death starts at $18 \pm 2 \mathrm{~h}$ vs. $4 \pm 1 \mathrm{~h} ; \mathrm{n}=9-12$ ).

\section{Zinc Staining}

Near-pure cortical neuronal cultures were loaded with $5 \mu \mathrm{M}$ Fluo-Zin3-AM for $30 \mathrm{~min}$ at $37^{\circ} \mathrm{C}$. Cultures were exposed to 800 $\mu \mathrm{M} 3-\mathrm{NPA}$ and $200 \mu \mathrm{M}$ 6-OHDA, $400 \mu \mathrm{M} \mathrm{MPP}^{+}, 25 \mu \mathrm{M}$ ethacrynic acid and $80 \mu \mathrm{M} \mathrm{H}_{2} \mathrm{O}_{2}$ (ROS generators, positive control). Increases in Fluo-Zin 3 fluorescence began at $6 \mathrm{~h}$ for 3-NPA and peaked at $8-12 \mathrm{~h}$, began at $2 \mathrm{~h}$ for the other toxins and peaked at $3 \mathrm{~h}$. Increases in Fluo-Zin 3 fluorescence were seen in striatal $/ \mathrm{mid}-$ brain cultures at lower levels of toxins $\left(5 \mu \mathrm{M} \mathrm{MPP}^{+}\right)$, but with similar kinetics. Striatal/midbrain cultures were coloaded with $5 \mu$ M Fluo-Zin3 (Invitrogen/Life Technologies, Carlsbad, Calif., USA) and $10 \mu \mathrm{M} 5-7$, dihydroxytryptamine (weakly identifies dopaminergic neurons) [19], and then exposed to $5 \mu \mathrm{M} \mathrm{MPP}$ for $3 \mathrm{~h}$. Epifluorescence photomicrographs were taken at equivalent exposures at $485 / 530$ for Fluo-Zin3 and 360/450 for 5-7,dihydroxytryptamine. For $\mathrm{Zn}^{2+}$ fluorescence in striatal sections, mice were sacrificed after $7 \times 3$-NPA injections $(50 \mathrm{mg} / \mathrm{kg}$ i.p. $2 \times /$ day $)$ and fresh frozen sections of striatum were made, dried and immediately stained in $5 \mu \mathrm{M}$ Zinpyr-1 (ZP1, TefLabs, Galveston, Tex., USA) for $2 \mathrm{~min}$, and washed $3 \times$ in phosphate-buffered saline (PBS). Epifluorescence photomicrographs were then taken at equivalent exposures at $485 / 530$.

\section{Immunofluorescent Technique}

Near-pure striatal/midbrain neuronal cultures were fixed, permeabilized in $0.4 \%$ Triton X-100, blocked in $10 \%$ normal goat serum, incubated with the primary antibody (anti-tyrosine hydroxylase (1:1,000), Chemicon/Millipore, Billerica, Mass., USA) 
and developed using goat anti-mouse-CY3 secondary antibodies (1:200). Tyrosine hydroxylase positive neurons $\left(\mathrm{TH}^{+},>300 /\right.$ pit for control) that remained in each pit were counted.

Determination of $\mathrm{NAD}^{+}$and $\mathrm{NADH}$ Levels

Near-pure cortical neuronal cultures (7-9 DIV), were used for the $\mathrm{NAD}^{+}$and $\mathrm{NADH}$ measurements; cultures were exposed to $800 \mu \mathrm{M} 3-\mathrm{NPA}$, or to $400 \mu \mathrm{M} \mathrm{MPP}^{+}$or $200 \mu \mathrm{M} 6$-OHDA. Cultures were then washed and lysed by addition of 75\% ethanol- $0.05 \mathrm{M}$ $\mathrm{K}_{2} \mathrm{HPO}_{4}$ after toxin exposure. $\mathrm{NAD}^{+}$and $\mathrm{NADH}$ were measured as described [21]. The $\mathrm{NAD}^{+} / \mathrm{NADH}$ ratio decreased starting at 12-14 $\mathrm{h}$ after 3-NPA exposure and was maximally reduced at $18 \mathrm{~h}$, whereas it decreased starting at $3 \mathrm{~h}$ and was maximally reduced at $4 \mathrm{~h}$ for $\mathrm{MPP}^{+}$and 6-OHDA which is just prior to the onset of cell death (data not shown).

\section{Determination of Dihydroxyacetone Phosphate and Fructose} Bisphosphate

Dihydroxyacetone phosphate (DHAP) and fructose bisphosphate (FBP) measurements were made on neuronal cell lysates prepared at the same timepoints and conditions, but were lysed by addition of $6 \%$ perchloric acid and protein precipitated by addition of potassium carbonate to $\mathrm{pH}$ 3.5. DHAP and FBP were measured as described [21].

In vivo Studies of Injections of 3-NPA into Rats or Mice

Long-Evans male rats (body weight: 250-300 g, Charles Rivers, Wilmington, Del., USA), C57/BL6J mice (Jackson Laboratories, Bar Harbor, Me., USA), or Wlds mice (Harlan, Loughborough, UK) were used in this study. Six rats or mice were used for each condition studied. Housing and anesthesia concurred with guidelines established by the Washington University and LSUHSC institutional Animal Studies Committee, and were in accordance with the PHS Guide for the Care and Use of Laboratory Animals, USDA regulations and the AVMA Panel on Euthanasia guidelines. Two groups of 6 rats were anesthetized with 40 $\mathrm{mg} / \mathrm{kg}$ pentobarbital intraperitoneally (i.p.), placed into a stereotax and injected with $750 \mathrm{nmol}$ of 3 -NPA in the presence or absence of $400 \mathrm{nmol}$ of pyruvate by direct stereotaxic microiontophoretic injection into the striatum at $2 \mu \mathrm{l} / \mathrm{min}(0.5 \mathrm{~mm}$ anterior bregma, $2.6 \mathrm{~mm}$ lateral bregma, $5 \mathrm{~mm}$ ventral bregma; the syringe was left in for $5 \mathrm{~min}$ after injection). Animals were monitored for $24 \mathrm{~h}$ and perfused with cold PBS on day 3 for 2,3,5-triphenyl tetrazolium chloride (TTC) staining. Subacute systemic intraperitoneal injections of 3-NPA in 16-week-old C57/Bl6 mice were performed as described [4]. Six Wld ${ }^{s}$ male mice aged 16 weeks were similarly exposed to 3-NPA. The surviving, nonakinetic animals from each of the 4 groups of 6 mice were behavior-tested and perfused for TTC staining on the evening of their last 3-NPA injection.

\section{Morphometric Analysis of Infarct Volume}

Infarct volumes were measured by morphometric analysis of infarct areas that were defined by a lack of staining in $2 \%$ TTC of 1- or 2-mm coronal sections using mouse or rat brain matrices, respectively (Harvard Bioscience, South Natick, Mass., USA). A cross-sectional area of the nonstained region for each brain slice was determined using an image analyzer (DUMAS, Drexel University, Philadelphia, Pa., USA) as described [22].
Semi-Quantitative Behavior Scoring of Mice

Mice were tested just prior to euthanasia for clasping, grasping strength and gait, using the tail inversion, inverted-screen and footprint-mapping tests. Animals were scored $0-5$ by a rater blinded to the experimental conditions; scores from all 3 tests were added for each mouse, and results are presented as mean \pm SEM ( $\mathrm{n}=$ 6). For tail inversion: $0=$ dead, $1=$ akinetic, $2=$ curled into a ball, $3=$ major clasping, $4=$ minor clasping and $5=$ no clasping. For inverted screen: $0=$ dead, $1=$ nongrasping/akinetic, $2=$ holding on for less than 2 s, 3 = holding on for 2-6 s, 4 = holding on for 6-12 s, and $5=$ holding on for longer than $12 \mathrm{~s}$ or 'climb over'. For footprint mapping: $0=$ dead, $1=$ akinetic, $2=$ hindlimb dragging, 3 = footprint nonoverlap $>1.5 \mathrm{~cm}, 4=$ footprint nonoverlap $0-1.5$ $\mathrm{cm}$, and $5=$ complete footprint overlap. Out of six 3 -NPA- or 3 -NPA + lactate-exposed mice, 3 or 2 died respectively, whereas only $1 \mathrm{Wld}^{\mathrm{s}}$ mouse and no $3-\mathrm{NPA}+$ pyruvate-exposed mice died.

\section{Data Analysis and Statistics}

The changes in neuronal death and intracellular $\mathrm{NAD}^{+}$ $\left(\left[\mathrm{NAD}^{+}\right]_{\mathrm{i}}\right)$ were determined in cultures under the conditions and genotypes stated. The mean \pm SEM were plotted and the $\mathrm{n}$ given for each experiment in the figure legends. Results were compared to sham-wash or saline-injection controls, as well as to toxin or injury exposure alone. One-way ANOVA was used to assess variance in each set of experiments, followed by a Bonferroni test. Significance was achieved by a $\mathrm{p}$ value of less than 0.05 .

\section{Reagents}

Unless otherwise stated, all reagents were from Sigma Chemical Co. (St. Louis, Mo., USA).

\section{Results}

\section{MPP ${ }^{+}, 6-O H D A$ and 3-NPA Caused Intracellular Zinc Release}

The toxins studied here ( $\mathrm{MPP}^{+}, 6-\mathrm{OHDA}$ and 3-NPA) have been reported to induce ROS, and ROS have been shown to induce $\left[\mathrm{Zn}^{2+}\right]_{\mathrm{i}}$ release [17]. We show that 3 or $8 \mathrm{~h}$ after exposure of striatal/midbrain or cortical neuronal cultures to toxic levels of these compounds (fig. 1a, b), $\left[\mathrm{Zn}^{2+}\right]_{\mathrm{i}}$ levels are optimally increased as measured using Fluo-Zin3 fluorescence dye microscopy. The increase observed in cortical neurons is equal to, or for 3-NPA greater than, the strong ROS generators, $\mathrm{H}_{2} \mathrm{O}_{2}$, or ethacrynic acid (quantified in fig. 1c). 5-7,Dihydroxy-tryptamine is at best a weak fluorescent marker for $\mathrm{TH}^{+}$neurons [19], and Fluo-Zin 3 fluorescence was also shown to increase after $\mathrm{MPP}^{+}$exposure in these neurons. The increase in $\left[\mathrm{Zn}^{2+}\right]_{i}$ was oxidant mediated and specific for zinc because trolox (antioxidant) and TPEN partially and fully attenuated the increase in $\left[\mathrm{Zn}^{2+}\right]_{\mathrm{i}}$ after 3-NPA, respectively (fig. 1c). The partial efficacy of antioxidants against each of these neurotoxins has been reported previously $[19,23,24]$. 
Fluo-Zin3
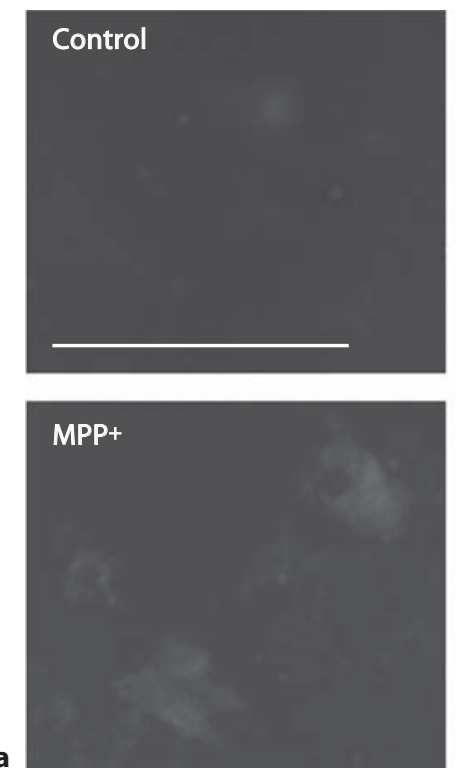

MPP+
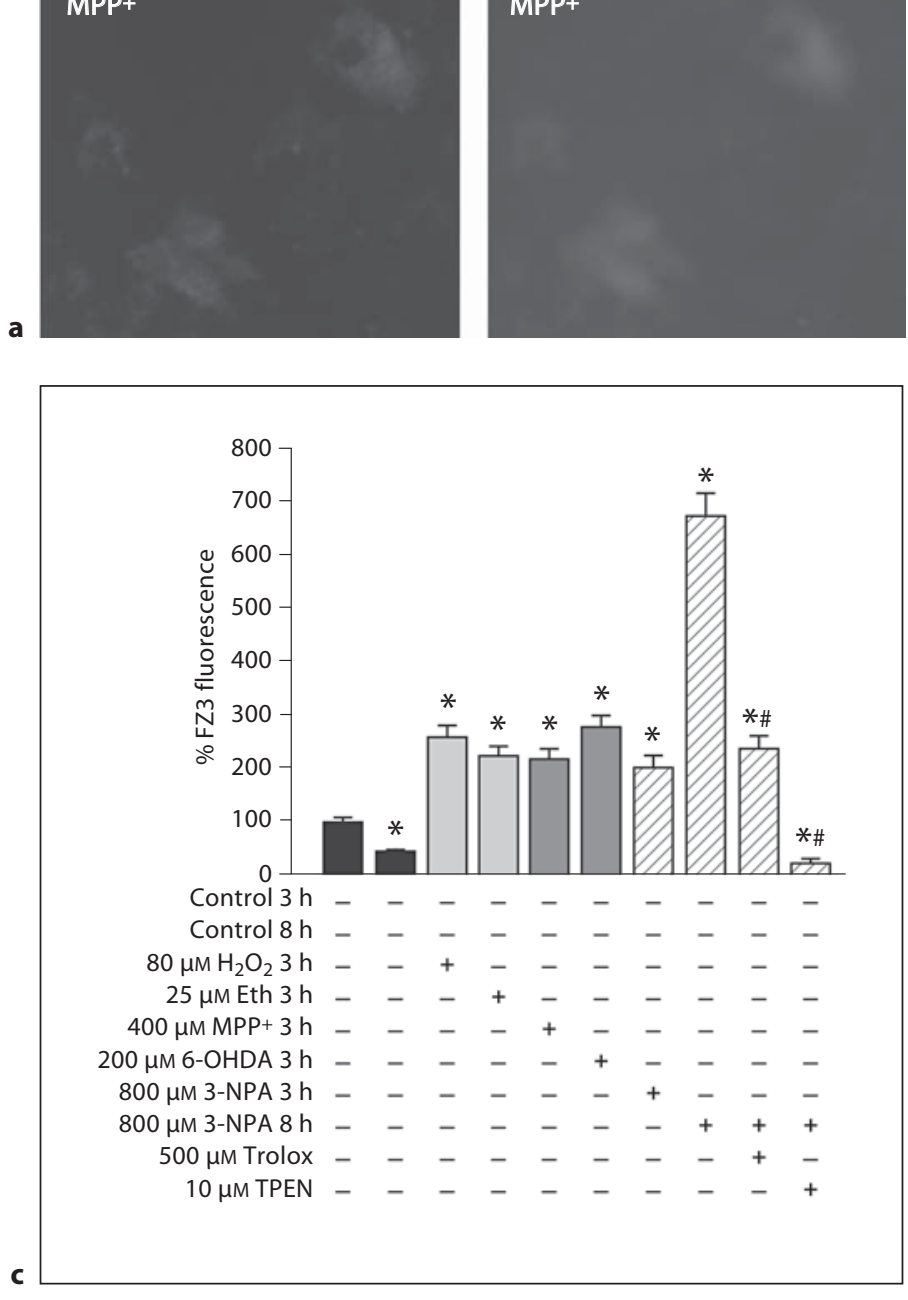

Compounds That Increase $\mathrm{NAD}^{+}$Levels Prevented

\section{3-NPA, 6-OHDA and MPP Toxicity}

The concentrations and time courses of the neurotoxins were chosen to result in approximately $50 \%$ neuronal death. The concentrations of compounds used to attenuate toxicity were optimized (data not shown). The therapeutic compounds pyruvate, nicotinamide, $\mathrm{NAD}^{+}$, sirti-
Fluo-Zin3
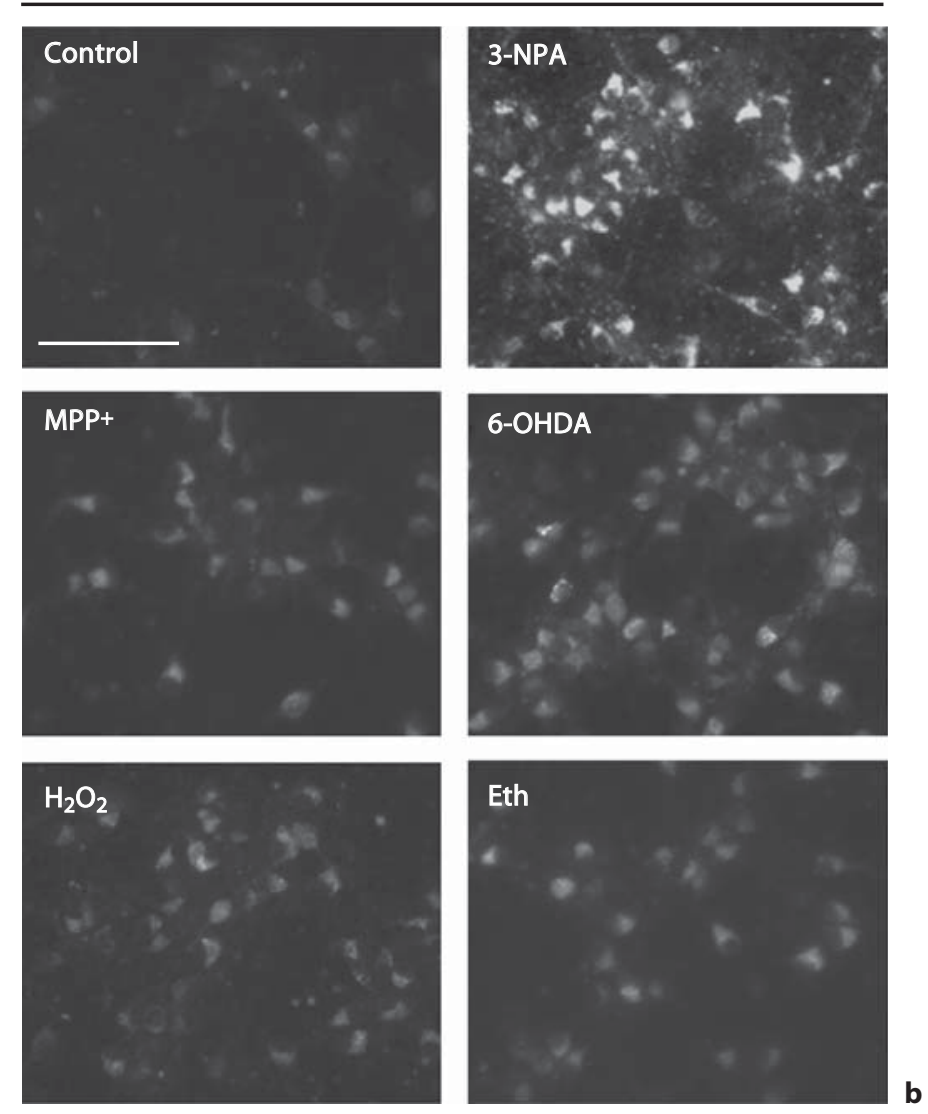

Fig. 1. Exposure to mitochondrial toxins induces an increase in $\left[\mathrm{Zn}^{2+}\right]_{\mathrm{i}}$ in dopamine-containing striatal/midbrain neurons and in cortical neurons. a Striatal/midbrain cultures were coloaded with $5 \mu \mathrm{M}$ Fluo-Zin3-AM $\left(\left[\mathrm{Zn}^{2+}\right]_{\mathrm{i}}\right)$ and $10 \mu \mathrm{M}$ 5-7,dihydroxytryptamine $\left(\mathrm{TH}^{+}\right)$, and then exposed to $5 \mu \mathrm{M} \mathrm{MPP}{ }^{+}$for $3 \mathrm{~h}$. Epifluorescence photomicrographs were taken at equivalent exposures for the control and $\mathrm{MPP}^{+}$exposed cultures at 485/530 for Fluo-Zin3, and at 360/450 for 5-7,dihydroxytryptamine. b Near-pure neuronal cultures were loaded with $5 \mu \mathrm{M}$ Fluo-Zin3-AM and exposed to $800 \mu \mathrm{M} 3-\mathrm{NPA}$ for 3 or $8 \mathrm{~h}$, or to $400 \mu \mathrm{M} \mathrm{MPP}, 200 \mu \mathrm{M}$ 6-OHDA, $25 \mu \mathrm{M}$ ethacrynic acid (Eth) or $80 \mu \mathrm{M} \mathrm{H}_{2} \mathrm{O}_{2}$ for $3 \mathrm{~h}$, and photomicrographs were taken as above. c The photomicrographs were quantitated using SISAnalysis software, and normalized to control levels. * Significant difference from control. * Significant difference from 3-NPA exposure at $\mathrm{p}<0.05$ by a Bonferonni test. Bars indicate $50 \mu \mathrm{m}$.

nol and TPEN were demonstrated to attenuate death induced by 3-NPA and $\mathrm{MPP}^{+}$in near-pure cortical neuronal cultures to varying extents (fig. 2). Sirtinol is an inhibitor of the sirtuin pathway, which is an $\mathrm{NAD}^{+}$catabolic deacetylase enzyme involved in transcriptional regulation. Neurotoxicity induced by 6-OHDA was not responsive to $\mathrm{Zn}^{2+}$ chelation (TPEN) or $\mathrm{Zn}^{2+}$ excess, but was 
Fig. 2. Pyruvate, nicotinamide, sirtinol, TPEN and $\mathrm{NAD}^{+}$attenuate neurotoxicity in PNC cultures induced by 3-NPA, 6-OHDA and $\mathrm{MPP}^{+}$. Near-pure cortical neuronal cultures were exposed as indicated. $\mathrm{LDH}$ released to the bathing medium after $24-48 \mathrm{~h}$ is plotted (mean \pm SEM, $\mathrm{n}=9-12$ cultures per condition); plot is scaled to the level associated with near complete neuronal death (produced by exposure to $20 \mu \mathrm{M} \mathrm{A} 23187$ for $24 \mathrm{~h}=100$ ). $*, \#,+$ Difference from neurotoxin exposure alone at $\mathrm{p}<0.05$ by 1 -way ANOVA followed by a Bonferroni test.

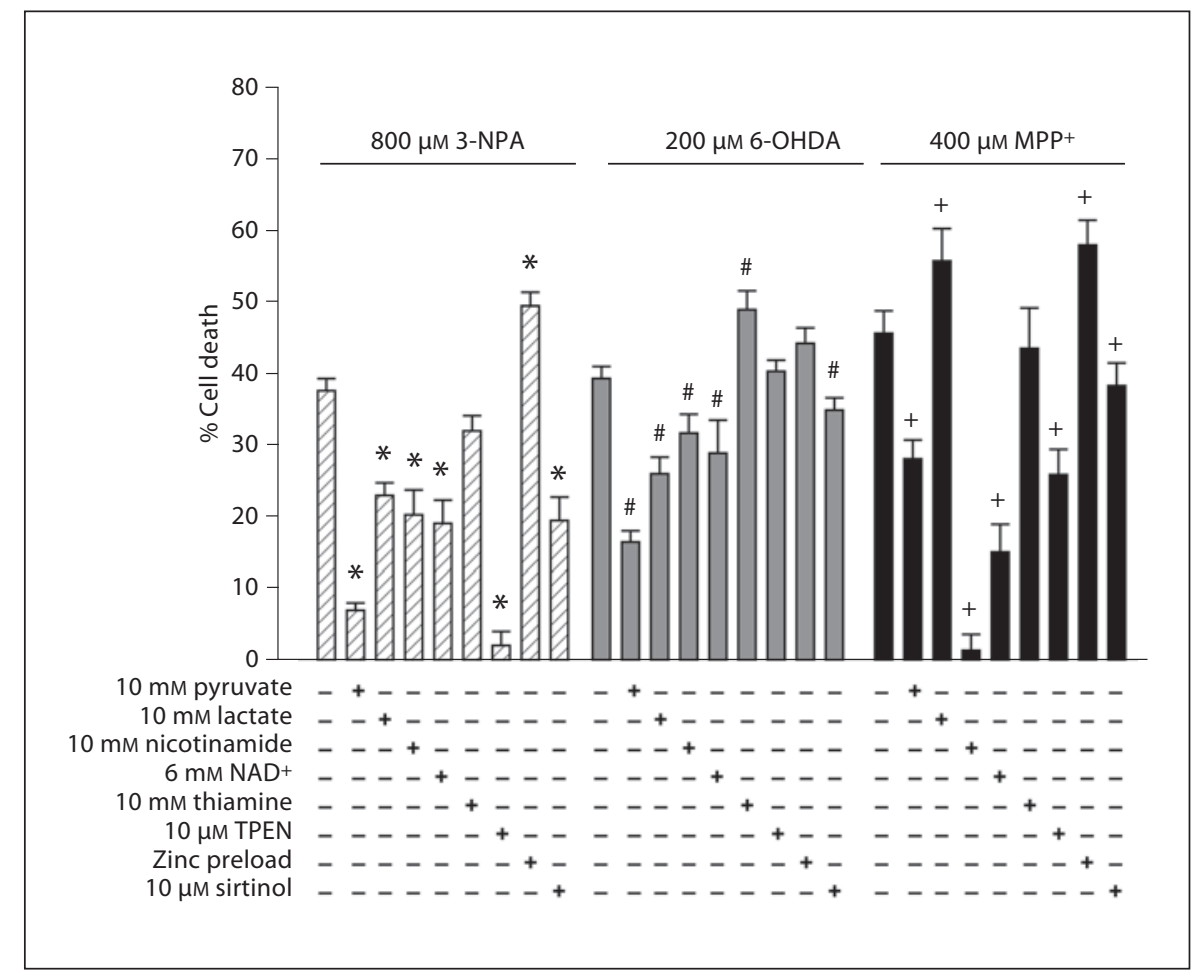

responsive to the restoration of $\mathrm{NAD}^{+}$levels (pyruvate, nicotinamide, $\mathrm{NAD}^{+}$and sirtinol). In contrast, equivalent concentrations of lactate were less effective than pyruvate for all toxins; lactate maintained partial efficacy for 3-NPA and 6-OHDA, but not for MPP+. Thiamine, a pyruvate dehydrogenase and $\alpha$-ketoglutarate dehydrogenase cofactor, was ineffective for all toxins. Pyruvate, nicotinamide, lactate, thiamine and $\mathrm{NAD}^{+}$do not chelate $\mathrm{Zn}^{2+}[17,25]$. Other than lactate, the beneficial compounds increase the intracellular concentration of $\mathrm{NAD}^{+}$ (table 1 and [17]). The number of $\mathrm{TH}^{+}$neurons was reduced by lower toxin exposures and restored by pyruvate, $\mathrm{NAD}^{+}$and TPEN in striatal/midbrain cultures, confirming that similar mechanisms are involved in $\mathrm{TH}^{+}$neurons (fig. 3).

\section{3-NPA, 6-OHDA and $M P P^{+}$Decreased the $N A D^{+} /$}

NADH Ratio, Which Was Prevented by Pyruvate,

Nicotinamide and $N A D^{+}$

Near-pure cortical neuronal cultures were exposed to 3-NPA for $18 \mathrm{~h}$ and to $\mathrm{MPP}^{+}$and 6-OHDA for $4 \mathrm{~h}$ (prior to cell death), which were optimal timepoints for the loss of metabolic intermediates (data not shown). Cultures were assayed for total $\mathrm{NAD}^{+}$and $\mathrm{NADH}$ content as stated in the Experimental Procedures section. These neurotox- ins all induced a substantial decrease in $\mathrm{NAD}^{+}$levels, and the effect was greatest for 6-OHDA. However, only $\mathrm{MPP}^{+}$ (and not 6-OHDA) induced a substantial increase in $\mathrm{NADH}$ levels, as expected for a mitochondrial complex I inhibitor. Extracellular pyruvate, nicotinamide and $\mathrm{NAD}^{+}$prevented the decrease in $\left[\mathrm{NAD}^{+}\right]_{i}$ levels for each neurotoxin; pyruvate did so at the expense of NADH levels, thereby restoring the $\mathrm{NAD}^{+} / \mathrm{NADH}$ ratio. Lactate did not significantly prevent the decrease in the $\mathrm{NAD}^{+}$/ $\mathrm{NADH}$ ratio (table 1).

\section{3-NPA, 6-OHDA and MPP Caused DHAP and FBP Accumulation Indicative of GAPDH Inhibition}

Cultures were similarly exposed and assayed for DHAP and FBP content as already stated. These neurotoxins (3-NPA, 6-OHDA and $\mathrm{MPP}^{+}$) all induced a substantial increase in these glycolytic intermediates indicative of glycolytic inhibition at GAPDH. The increase in DHAP and FBP was greatest for 3-NPA. Extracellular pyruvate, nicotinamide and $\mathrm{NAD}^{+}$restored the intracellular levels of DHAP and FBP, demonstrating that the glycolytic inhibition was indirect and mediated through the $\mathrm{NAD}^{+} / \mathrm{NADH}$ ratio. Lactate partially reduced the increase in DHAP and FBP levels after 3-NPA, but not to the extent of pyruvate or $\mathrm{NAD}^{+}$(table 2 ). 
Table 1. 3-NPA, 6-OHDA and $\mathrm{MPP}^{+}$each reduce the $\mathrm{NAD}^{+}$/ $\mathrm{NADH}$ ratio

\begin{tabular}{lccc}
\hline Condition & $\begin{array}{l}\mathrm{NAD}^{+} \\
(\mathrm{nmol} / \mathrm{plate} \\
\pm \mathrm{SEM})\end{array}$ & $\begin{array}{l}\text { NADH } \\
(\mathrm{nmol} / \mathrm{plate} \\
\pm \mathrm{SEM})\end{array}$ & $\begin{array}{l}\text { NAD }{ }^{+} / \\
\text {NADH ratio } \\
( \pm \mathrm{SEM})\end{array}$ \\
\hline Sham wash & $4.06 \pm 0.22$ & $0.85 \pm 0.12$ & $4.8 \pm 0.46$ \\
1 mM 3-NPA & $2.01 \pm 0.41^{*}$ & $0.99 \pm 0.16$ & $2.0 \pm 0.71^{*}$ \\
3-NPA + pyruvate & $3.28 \pm 1.34^{\#}$ & $0.41 \pm 0.21^{\#}$ & $8.0 \pm 1.66^{*, \#}$ \\
3-NPA + lactate & $2.68 \pm 0.69^{*}$ & $1.1 \pm 0.25$ & $2.44 \pm 1.0^{*}$ \\
3-NPA + nicotinamide & $5.61 \pm 0.86^{\#}$ & $0.99 \pm 0.07$ & $5.7 \pm 1.01^{\#}$ \\
3-NPA + NAD & $6.2 \pm 0.98^{+}$ & $1.1 \pm 0.27$ & $5.6 \pm 1.16^{\#}$ \\
400 $\mu \mathrm{M}$ MPP & $1.95 \pm 0.40^{*}$ & $2.36 \pm 0.58^{*}$ & $0.83 \pm 0.96^{*}$ \\
$\mathrm{MPP}^{+}+$pyruvate & $2.86 \pm 0.48^{*, \#}$ & $1.14 \pm 0.20^{\#}$ & $2.5 \pm 0.76^{*, \#}$ \\
$\mathrm{MPP}^{+}+$lactate & $1.80 \pm 0.43^{*}$ & $2.55 \pm 0.70^{*}$ & $0.71 \pm 0.99^{*}$ \\
$\mathrm{MPP}^{+}+$nicotinamide & $4.31 \pm 0.38^{\#}$ & $2.25 \pm 0.41^{*}$ & $1.9 \pm 0.85^{*, \#}$ \\
MPP $^{+}+\mathrm{NAD}^{+}$ & $5.93 \pm 0.46^{\#}$ & $2.17 \pm 0.48^{*}$ & $2.7 \pm 0.96^{*, \#}$ \\
200 $\mu \mathrm{M}$ 6-OHDA & $0.22 \pm 0.03^{*}$ & $0.64 \pm 0.03$ & $0.34 \pm 0.10^{*}$ \\
6-OHDA + pyruvate & $2.04 \pm 0.29^{\#}$ & $0.61 \pm 0.18$ & $3.3 \pm 0.61^{*, \#}$ \\
6-OHDA + nicotinamide & $1.88 \pm 0.12^{\#}$ & $0.63 \pm 0.14$ & $3.0 \pm 0.46^{*, \#}$ \\
6-OHDA + NAD & $4.2 \pm 0.32^{*}$ & $0.90 \pm 0.19$ & $4.7 \pm 0.62^{\#}$ \\
\hline
\end{tabular}

Near-pure cortical neuronal cultures were exposed to 3-NPA for $18 \mathrm{~h}$, and to $\mathrm{MPP}^{+}$or 6-OHDA for $4 \mathrm{~h}$ as indicated. $\mathrm{NAD}^{+}$and NADH levels were measured prior to cell death (nmol/plate \pm SEM, $\mathrm{n}=6-9$ measurements per condition).

* Significant difference from sham-wash control.

\# Significant difference from neurotoxin alone at $\mathrm{p}<0.05$ by 1 -way ANOVA followed by a Bonferroni test.

Table 2. 3-NPA, $\mathrm{MPP}^{+}$and 6-OHDA increase levels of DHAP and FBP which are restored by pyruvate, nicotinamide or $\mathrm{NAD}^{+}$

\begin{tabular}{lcc}
\hline Condition & $\begin{array}{c}\text { DHAP (nmol/ } \\
\text { plate } \pm \text { SEM) }\end{array}$ & $\begin{array}{c}\text { FBP (nmol/ } \\
\text { plate } \pm \text { SEM) }\end{array}$ \\
\hline Sham wash & $2.0 \pm 0.7$ & $2.1 \pm 0.9$ \\
1 mM 3-NPA & $10.1 \pm 0.2^{*}$ & $20.5 \pm 5.9^{*}$ \\
3-NPA + pyruvate & $2.9 \pm 0.2^{\#}$ & $4.4 \pm 0.2^{\#, *}$ \\
3-NPA + lactate & $6.2 \pm 0.4^{\#, *}$ & $8.9 \pm 1.2^{\#, *}$ \\
3-NPA + NAD ${ }^{+}$ & $3.4 \pm 0.4^{\#}$ & $4.9 \pm 0.2^{\#, *}$ \\
$400 \mu M$ MPP & $3.7 \pm 0.2^{*}$ & $4.0 \pm 0.3^{*}$ \\
MPP $^{+}+$nicotinamide & $1.9 \pm 0.3^{\#}$ & $2.5 \pm 0.2^{\#}$ \\
MPP $^{+}+\mathrm{NAD}^{+}$ & $2.2 \pm 0.3^{\#}$ & $2.6 \pm 0.2^{\#}$ \\
200 $\mu \mathrm{M}$ 6-OHDA & $7.2 \pm 0.7^{*}$ & $8.4 \pm 0.8^{*}$ \\
6-OHDA + pyruvate & $2.2 \pm 0.6^{\#}$ & $2.4 \pm 0.7^{\#}$ \\
6-OHDA + nicotinamide & $2.4 \pm 0.4^{\#}$ & $2.9 \pm 0.5^{\#}$ \\
6-OHDA + NAD & $2.5 \pm 0.6^{\#}$ & $3.1 \pm 0.4^{\#}$ \\
\hline
\end{tabular}

Near-pure cortical neuronal cultures were exposed to 3-NPA for $18 \mathrm{~h}$, and to $\mathrm{MPP}^{+}$or 6-OHDA for $4 \mathrm{~h}$ as indicated. DHAP and FBP levels were measured prior to cell death (nmol/plate \pm SEM, $\mathrm{n}=6-9$ measurements per condition).

* Significant difference from sham-wash control.

\# Significant difference from neurotoxin alone at $\mathrm{p}<0.05$ by 1 -way ANOVA followed by a Bonferroni test.

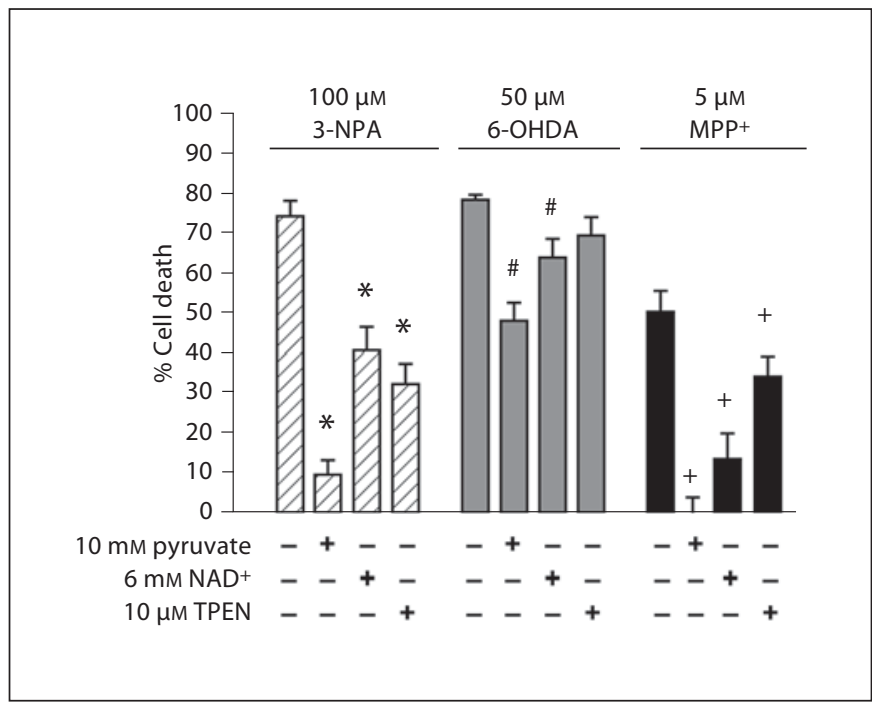

Fig. 3. Pyruvate, $\mathrm{TPEN}$ and $\mathrm{NAD}^{+}$attenuate $\mathrm{TH}^{+}$neuronal loss in striatal/midbrain cultures induced by 3-NPA, 6-OHDA and $\mathrm{MPP}^{+}$. Striatal/midbrain neuronal cultures from Swiss-Webster mice were exposed as indicated. The percentage of $\mathrm{TH}^{+}$neuronal death after $24-48 \mathrm{~h}$ is plotted (mean \pm SEM, $\mathrm{n}=6-9$ cultures per condition). ${ }^{*},+$ Difference from neurotoxin exposure alone at $\mathrm{p}<0.05$ by 1 -way ANOVA followed by a Bonferroni test.

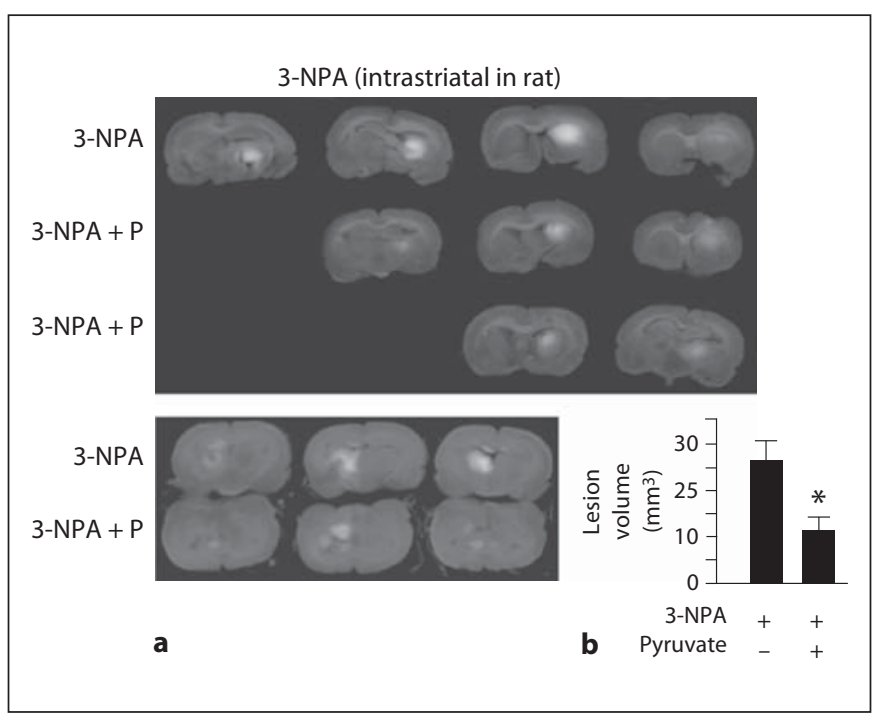

Fig. 4. Pyruvate $(\mathrm{P})$ reduced the infarct volume induced by intrastriatal injection of 3-NPA. a 3-NPA $(750 \mathrm{nmol})$ was injected into the striatum of rats in the presence or absence of $400 \mathrm{nmol}$ of pyruvate, and TTC staining was performed after 3 days as indicated. Each row shows the injured tissue from a different animal that was exposed as indicated. $\mathbf{b}$ The lesion volume was measured. Average \pm SEM, $(n=6)$ is presented. * Difference from neurotoxin exposure alone at $\mathrm{p}<0.05$ by 1 -way ANOVA followed by a Bonferroni test. 


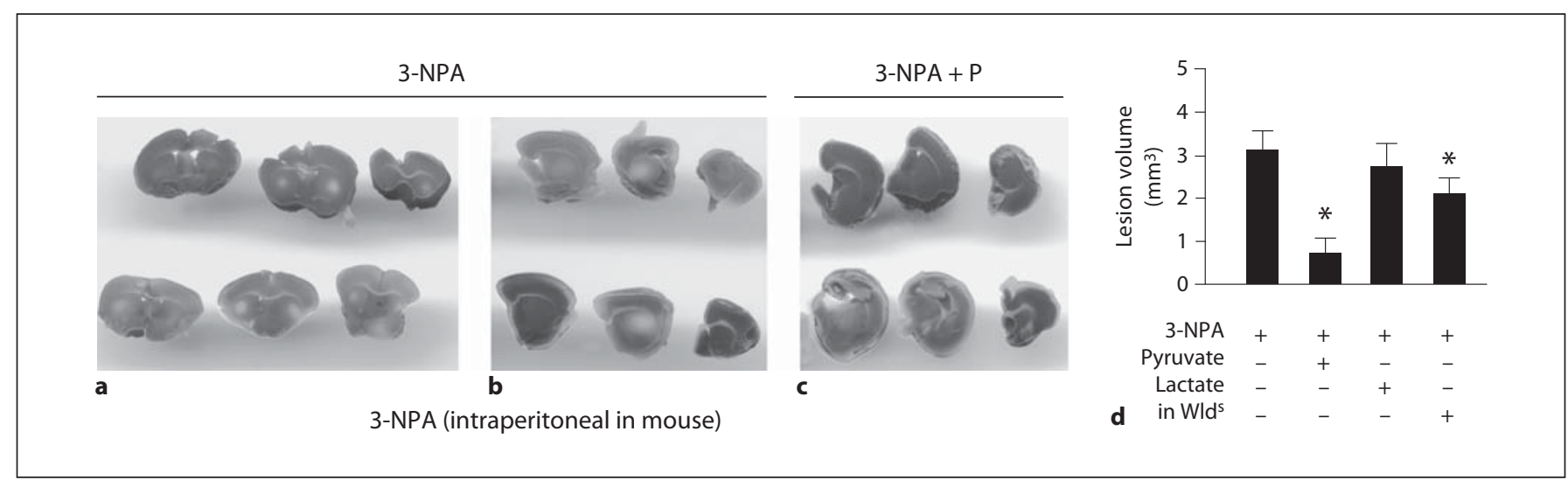

Fig. 5. Pyruvate $(\mathrm{P})$ or a Wld $\mathrm{W}^{\mathrm{s}}$ genotype reduced the infarct volume caused by i.p. 3-NPA in mice. a-d 3-NPA (9 injections of $50 \mathrm{mg} / \mathrm{kg}$ $2 \times /$ day) was injected i.p. into $\mathrm{C} 57 / \mathrm{Bl} 6$ or $\mathrm{Wld}^{\mathrm{s}}$ mice with or without $500 \mathrm{mg} / \mathrm{kg}$ i.p. of pyruvate or lactate (once per day starting 1 day before), and TTC staining was performed after 7 days as indicated. Each row shows the injured tissue from a different animal that was exposed as indicated. a Coronal sections of 2 different
3-NPA-injected C57/Bl6 mice are shown to demonstrate the bilateral lesion. b One hemisphere of 2 different 3-NPA-injected C57/ $\mathrm{Bl} 6$ mice is shown (other half saved for biochemical assays). c One hemisphere of 2 different $3-\mathrm{NPA}+$ pyruvate-injected C57/B16 mice is shown. $\mathbf{d}$ The lesion volume was measured and the average \pm SEM $(n=6)$ is presented. * Difference from neurotoxin exposure alone at $\mathrm{p}<0.05$ by 1 -way ANOVA followed by a Bonferroni test.
Injections of 3-NPA Induced Striatal Lesions Which Could Be Prevented by Pyruvate, Nicotinamide, but Not by Lactate

Long-Evans male rats were injected with high doses of 3-NPA into the striatum $(750 \mathrm{nmol})$ in the presence or absence of pyruvate; lesion volume was determined after 3 days. We also determined lesion volumes induced by 9 low-dose intraperitoneal injections of 3-NPA into mice. Pyruvate attenuated the lesions in both the rat intrastriatal injections (fig. 4) and in the mouse intraperitoneal injections (fig. 5). Nicotinamide, but not lactate, was also effective at attenuating lesions induced both by intrastriatal or intraperitoneal injections of 3-NPA (data not shown, fig. 4) [26]. Furthermore, Wld ${ }^{\mathrm{s}}$ mice also had smaller lesions after 3-NPA administration. Cortical neuronal cultures derived from Wld $\mathrm{Wl}^{\mathrm{s}}$ mice were also resistant to each of the 3 toxins, and the therapeutic compounds further attenuated neurotoxicity (online suppl. fig. 1b; for all online supplementary material, see www.karger.com/doi/10.1159/000336558). Cortical neuronal cultures derived from mice with a genetic deletion of the $\mathrm{Zn}^{2+}$ homeostatic proteins, zinc transporter 3 (ZnT3 KO, no synaptic zinc), or metallothionein 3 (MT3 KO, reduced $\left[\mathrm{Zn}^{2+}\right]_{\mathrm{i}}$ ) were not significantly different in their sensitivities to the toxins (online suppl. fig. 1a).
Injections of 3-NPA Induced Behavioral Deficits That Could Be Prevented by Pyruvate, but Not by Lactate

Figure 6 shows the mean \pm SEM of the summed scores from 3 behavioral tests of each mouse: inverted screen, tail inversion and footprint mapping. The results from each individual test were similar to the combined results. In the animals receiving 3-NPA alone (that scored $0,0,0,10,9$ and 5) or 3-NPA + lactate (that scored $0,0,3,10,10$ and 7$), 50 \%$ were dead or completely moribund, and the gait and strength of the remainder were very abnormal at the time of sacrifice. In those mice receiving pyruvate (that scored 15, 15, 15, 11, 10 and 10), all were active and had a nearly normal gait, normal strength and little clasping behavior. In Wld ${ }^{\mathrm{s}}$ mice (that scored $0,10,12,10,9$ and 7), one mouse died and the behavioral deficits in the remainder were intermediate (fig. 6).

\section{Discussion}

We have previously demonstrated that exogenous $\mathrm{Zn}^{2+}[21,27]$ or oxidant-induced $\left[\mathrm{Zn}^{2+}\right]_{\mathrm{i}}$ release [17] causes selective loss of $\mathrm{NAD}^{+}$levels, glycolytic inhibition (causing a buildup of the intermediates DHAP and FBP), ATP depletion and neuronal death. Manipulations that prevent $\mathrm{Zn}^{2+}$ accumulation (chelation) or restore $\mathrm{NAD}^{+}$levels (exposure to pyruvate, nicotinamide, $\mathrm{NAD}^{+}$and sir- 


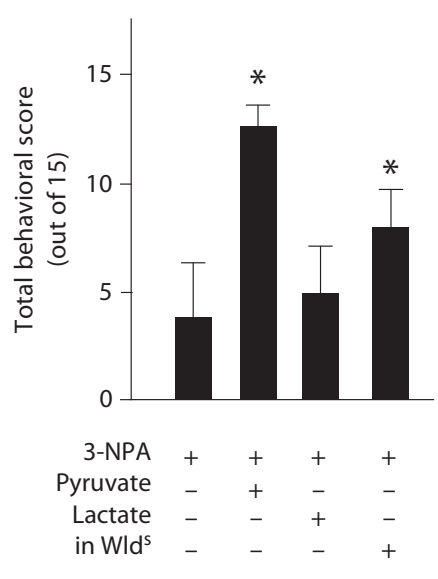

Fig. 6. Pyruvate reduced the gait deficits induced by i.p. 3-NPA. Before euthanizing the animals from figure 5, behavioral testing was performed as stated. The scores on the 3 semi-quantitative behavioral tests $(0-5)$ were measured and summed for each animal, and the average \pm SEM, $(n=6)$ is presented. * Difference from neurotoxin exposure alone at $\mathrm{p}<0.05$ by 1 -way ANOVA followed by a Bonferroni test.

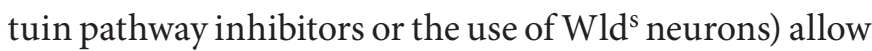
for glycolytic flux and reduce $\mathrm{Zn}^{2+}$-mediated neurotoxicities in vitro and in vivo. $\mathrm{Zn}^{2+}$ chelation attenuates 3-NPA and $\mathrm{MPP}^{+}$toxicity and pyruvate, nicotinamide and the direct application of $\mathrm{NAD}^{+}$attenuate 3-NPA, $\mathrm{MPP}^{+}$and 6-OHDA toxicities. These data strongly implicate a reduction in the $\mathrm{NAD}^{+} / \mathrm{NADH}$ ratio as an important mechanism, with $\mathrm{Zn}^{2+}$-mediation for 3-NPA and $\mathrm{MPP}^{+}$(see: this paper and [26]). $\mathrm{Zn}^{2+}$ accumulation has now been demonstrated for each of these neurotoxins in vitro and for 3-NPA and MPTP in vivo (online suppl. fig. 2 and $[8,15,16])$. Because subacute 3-NPA lesions form over 5-7 days, $\mathrm{Zn}^{2+}$ chelator studies are difficult to perform, requiring multiple intracerebral ventricular injections. ROS have been implicated in both the toxicities of these compounds and in the diseases they model, and antioxidants were shown to be partially effective (reviewed in $[28,29])$. Studies of these toxins suggest that their mechanisms of injury rely on ROS generation induced by mitochondrial inhibition (reviewed in [30, 31]). ROS scavengers protect against each of these neurotoxins $[19,23,24]$. In addition, a combination of an antioxidant and a mitochondrial activator improves motor performance and extends survival in the R6/2-expanded polyglutamine repeat mouse model of HD [32]. Mitochondrial dysfunction has also been demonstrated in patients and in genetic models of PD (e.g. parkin and synuclein), and in patients and genetic models of HD (CAG repeat models) (reviewed in [33-35]).

However, 6-OHDA toxicity, when compared to $\mathrm{MPP}^{+}$ or 3-NPA toxicity was relatively unresponsive to sirtuin inhibition, $\mathrm{Zn}^{2+}$ chelation or $\mathrm{Zn}^{2+}$ loading (fig. 2, 3). This may be because 6-OHDA had already induced maximal $\mathrm{NAD}^{+}$loss through an alternate mechanism (table 1), such that $\mathrm{Zn}^{2+}$-mediated loss of $\mathrm{NAD}^{+}$is less important. We suggest that the ROS generated by these toxins cause the $\mathrm{Zn}^{2+}$ release and accumulation. The differential cell selectivity of these inhibitors likely results from a combination of their differential uptake or activation and the differential susceptibility of the vulnerable regions to oxidative stress and mitochondrial dysfunction $[3,30]$. For 3 -NPA and MPP+, the increase in $\left[\mathrm{Zn}^{2+}\right]_{i}$ could cause the loss of $\mathrm{NAD}^{+}$, or it could exacerbate the $\mathrm{NAD}^{+}$loss induced by the toxins.

$\mathrm{MPP}^{+}$(but not 6-OHDA) induced a reduction in $\mathrm{NAD}^{+}$levels with a proportionate increase in $\mathrm{NADH}$ levels, which resulted in glycolytic inhibition. This is consistent with the known inhibition of mitochondrial $\mathrm{NADH}$ dehydrogenase by $\mathrm{MPP}^{+}$. 3-NPA, and particularly 6-OHDA, induced a reduction in $\mathrm{NAD}^{+}$levels without an increase in $\mathrm{NADH}$ levels. This suggests a mechanism involving catabolism of $\mathrm{NAD}^{+}$that results in a block of glycolysis (tables 1,2). Restoration of $\mathrm{NAD}^{+}$ levels by pyruvate, nicotinamide or $\mathrm{NAD}^{+}$prevents glycolytic inhibition and death, irrespective of the source of the dyshomeostasis in the $\mathrm{NAD}^{+} / \mathrm{NADH}$ ratio. Because 6-OHDA is unresponsive to $\mathrm{Zn}^{2+}$ chelation, it is also possible that it acts through a non- $\mathrm{Zn}^{2+}$-mediated mechanism to induce $\mathrm{NAD}^{+}$loss, perhaps by activating polyADP ribosyl polymerase (PARP) (online suppl. fig. 3). PARP is activated by $3-\mathrm{NPA}$ and MPTP, causing a loss of $\mathrm{NAD}^{+}$levels; PARP inhibition is effective against these neurotoxicities in vivo [26, 36-38]. A similar PARP-mediated mechanism has not been reported for 6-OHDA neurotoxicity, though the dramatic loss of $\mathrm{NAD}^{+}$levels and the efficacy of nicotinamide suggest that PARP1 knockout animals should be partially resistant to 3NPA and 6-OHDA, as has been shown for MPTP [39]. $W{ }^{s}$ mice overexpressed the $\mathrm{NAD}^{+}$synthetic enzyme NMNAT1, allowing better $\mathrm{NAD}^{+}$restoration [40], and they had reduced susceptibility to MPTP-induced nigrostriatal degeneration [41]. They also displayed a dramatically reduced cell loss and $\mathrm{Zn}^{2+}$ fluorescence after target deprivation [17], as well as a modestly reduced 3-NPA lesion volume (fig. 5). Measurements of wild-type and $\mathrm{Wld}^{s}$ striatal $\mathrm{NAD}^{+}$levels after 3-NPA exposure are 
ongoing. Neurons derived from Wld $\mathrm{W}^{\mathrm{s}}$ mice were resistant to each of these mitochondrial toxins, and were synergistic with nicotinamide (online suppl. fig. 1), which mimics its effect on neuronal death mediated by another Complex I inhibitor, rotenone [42]. Neurons from ZnT3 KO or MT3 KO were not resistant to toxicity from 3-NPA, 6-OHDA or $\mathrm{MPP}^{+}$. ZnT3 is the $\mathrm{Zn}^{2+}$ transporter which loads synaptic zinc [43]. MT3 is the metallothionein present in neurons, and is a zinc homeostatic protein and an antioxidant [44]. The ZnT3 $\mathrm{KO}$ data is not surprising because synaptic release of zinc is unlikely to be involved in vitro due to the large culture volumes. However, the lack of effect of MT3 KO on neuronal toxicity is somewhat surprising, and suggests that the role of MT3 as an antioxidant protein is equally important as its role as an $\left[\mathrm{Zn}^{2+}\right]_{\mathrm{i}}$ homeostasis protein in these in vitro toxicities.

We demonstrate here that when the $\left[\mathrm{NAD}^{+}\right]_{\mathrm{i}}$ levels were maintained by pyruvate conversion to lactate, by nicotinamide precursor supplementation (and $\mathrm{NAD}^{+}$ catabolic blocker), or by direct extracellular $\mathrm{NAD}^{+}$supplementation, then glycolytic inhibition and death induced by mitochondrial toxins were prevented. Pyruvate was previously shown to attenuate $\mathrm{MPP}^{+}$-induced and 6-OHDA-induced neurotoxicities. However, the mechanism for this efficacy was suggested to be due to its antioxidant capabilities, whereas here we demonstrate that pyruvate acts by restoring the $\mathrm{NAD}^{+} / \mathrm{NADH}$ ratio [4547]. Powerful ROS scavengers have only been shown to moderately attenuate $(<50 \%)$ these mitochondrial inhibitors, whereas pyruvate was more efficacious both in vitro and in vivo. Also, pyruvate is not an antioxidant in the usual sense of absorbing excess electrons. Rather, its antioxidant effect results from the ability of alpha-ketoacids to undergo nonenzymatic decarboxylation in the pres- ence of $\mathrm{H}_{2} \mathrm{O}_{2}$ causing their mutual destruction [48]. By withdrawing $\mathrm{H}_{2} \mathrm{O}_{2}$, this mildly reduces levels of other oxidative species via Fenton chemistry reactions. Pyruvate was ineffective against redox active metal toxicity $\left(\mathrm{Cu}^{2+}\right.$, $\mathrm{Cd}^{2+}$ ) and much less effective against ethacrynic acid or menadione toxicities (ROS-mediated), suggesting its relative weakness as a normal antioxidant $[22,49,50]$. We suggest that pyruvate (and nicotinamide or $\mathrm{NAD}^{+}$) restores the $\mathrm{NAD}^{+} / \mathrm{NADH}$ ratio, whether the cause of the decrease is complex 1 inhibition $\left(\mathrm{MPP}^{+}\right)$, PARP-1 activation $\left(\mathrm{MPP}^{+}\right.$or 6-OHDA), or $\mathrm{Zn}^{2+}$-mediated $\mathrm{NAD}^{+}$loss (3-NPA or $\mathrm{MPP}^{+}$). This restoration of the $\mathrm{NAD}^{+} / \mathrm{NADH}$ ratio allows glycolytic flux. Exogenous lactate is unable to restore the $\mathrm{NAD}^{+} / \mathrm{NADH}$ ratio, but may be beneficial to remaining astrocytes or as an additional energy substrate.

Thiamine had no beneficial effect on 3-NPA, 6-OHDA or $\mathrm{MPP}^{+}$neurotoxicity. This suggests that in contrast to redox active metals or exogenous oxidative agents, direct ROS-mediated pyruvate dehydrogenase or $\alpha$-ketoglutarate dehydrogenase inhibition might not be involved in the neurotoxicity of these neurotoxins. These data suggest that 3-NPA and $\mathrm{MPP}^{+}$cause a ROS-mediated insult leading to $\mathrm{Zn}^{2+}$ accumulation and $\mathrm{NAD}^{+}$loss resulting in glycolytic blockade, which are all necessary for neuronal death. Non- $\mathrm{Zn}^{2+}$-mediated $\mathrm{NAD}^{+}$loss, especially for 6-OHDA, also contributes to neuronal death. It also suggests that these compounds should be investigated for their efficacy against HD and PD.

\section{Acknowledgements}

We would like to thank Darlene Guillot for assistance with graphics and Ryan Labadens for scientific editing. This work was funded by NIH grants NS030337 and DK073446 (C.T.S.).

\section{References}

1 Beal MF: Energetics in the pathogenesis of neurodegenerative diseases. Trends Neurosci 2000;23:298-304.

2 Reddy PH, Williams M, Tagle DA: Recent advances in understanding the pathogenesis of Huntington's disease. Trends Neurosci 1999;22:248-255.

-3 Browne SE, Bowling AC, MacGarvey U, Baik MJ, Berger SC, Muqit MM, Bird ED, Beal MF: Oxidative damage and metabolic dysfunction in Huntington's disease: selective vulnerability of the basal ganglia. Ann Neurol 1997;41:646-653.
4 Beal MF, Brouillet E, Jenkins BG, Ferrante RJ, Kowall NW, Miller JM, Storey E, Srivastava R, Rosen BR, Hyman BT: Neurochemi$\mathrm{cal}$ and histologic characterization of striatal excitotoxic lesions produced by the mitochondrial toxin 3-nitroproprionic acid. J Neurosci 1993;13:4181-4192.

5 Ludolph AC, He F, Spencer PS, Hammerstad J, Sabri M: 3-Nitropropionic acid-exogenous animal neurotoxin and possible human striatal toxin. Can J Neurol Sci 1991;18:492-498.

6 Browne SE, Beal MF: The energetics of Huntington's disease. Neurochem Res 2004;29: 531-546.
7 Kim GW, Chan PH: Involvement of superoxide in excitotoxicity and DNA fragmentation in striatal vulnerability in mice after treatment with the mitochondrial toxin, 3-nitropropionic acid. J Cereb Blood Flow Metab 2002;22:798-809.

-8 Wei G, Hough CJ, Sarvey JM: The mitochondrial toxin, 3-nitropropionic acid, induces extracellular $\mathrm{Zn} 2+$ accumulation in rat hippocampus slices. Neurosci Lett 2004;370: 118-122. 
-9 Fahn S, Cohen G: The oxidant stress hypothesis in Parkinson's Disease: evidence supporting it. Ann Neurol 1992;32:804-812.

10 Jenner P, Olanow CW: Oxidative stress and the pathogenesis of Parkinson's disease. Neurology 1996;47:S161-S170.

$\checkmark 11$ Jellinger K, Linert L, Kienzl E, Herlinger E, Youdim MB: Chemical evidence for 6-hydroxydopamine to be an endogenous toxic factor in the pathogenesis of Parkinson's disease. J Neural Transm Suppl 1995;46:297-314.

$\checkmark 12$ Andrew R, Watson DG, Best SA, Midgley JM, Wenlong H, Petty RK: The determination of hydroxydopamines and other trace amines in the urine of parkinsonian patients and normal controls. Neurochem Res 1993; 18:1175-1177.

13 Choi WS, Yoon SY, Oh TH, Choi EJ, O’Malley $\mathrm{KL}$, Oh YJ: Two distinct mechanisms are involved in 6-hydroxydopamine- and MPP+induced dopaminergic neuronal cell death: role of caspases, ROS, and JNK. J Neurosci Res 1999;57:86-94.

14 Fonck C, Baudry M: Toxic effects of MPP(+) and MPTP in PC12 cells independent of reactive oxygen species formation. Brain Res 2001;905:199-206.

15 Lee JY, Son HJ, Choi JH, Cho E, Kim J, Chung SJ, Hwang O, Koh JY: Cytosolic labile zinc accumulation in degenerating dopaminergic neurons of mouse brain after MPTP treatment. Brain Res 2009;1286:208-214.

- 16 Rojas P, Franco-Perez JE, Rojas C, RojasCastaneda J, Ebadi M, Fernandez-Valverde F, Serrano-Garcia N: Reduction of zinc-positive terminal fields in striatum of mouse after 1-methyl-4-phenylpyridinium neurotoxicity. Neurotoxicology 2005;26:959-968.

$\checkmark 17$ Sheline CT, Cai AL, Zhu J, Shi C: Serum or target deprivation-induced neuronal death causes oxidative neuronal accumulation of Zn2+ and loss of NAD+. Eur J Neurosci 2010; 32:894-904.

18 Sheline CT, Choi DW: Neuronal death in cultured murine cortical cells is induced by inhibition of GAPDH and triosephosphate isomerase. Neurobiol Dis 1998;5:47-54.

$\checkmark 19$ Lotharius J, Dugan LL, O’Malley KL: Distinct mechanisms underlie neurotoxin-mediated cell death in cultured dopaminergic neurons. J Neurosci 1999;19:1284-1293.

20 Ying H, Gottron F, Choi D: Assessment of cell viability in primary neuronal cultures. Curr Protoc Neurosci 2001; 7:(chapt 7)18.

21 Cai AL, Zipfel GJ, Sheline CT: Zinc neurotoxicity is dependent on intracellular NAD levels and the sirtuin pathway. Eur J Neurosci 2006;24:2169-2176.

22 Sheline CT, Wei L: Free radical-mediated neurotoxicity may be caused by inhibition of mitochondrial dehydrogenases in vitro and in vivo. Neuroscience 2006;140:235-246.

-23 Yang L, Calingasan NY, Chen J, Ley JJ, Becker DA, Beal MF: A novel azulenyl nitrone antioxidant protects against MPTP and 3-nitropropionic acid neurotoxicities. Exp Neurol 2005;191:86-93.
24 Cleren C, Calingasan NY, Chen J, Beal MF: Celastrol protects against MPTP- and 3-nitropropionic acid-induced neurotoxicity. J Neurochem 2005;94:995-1004.

25 Martell AM, Smith RM, Motekaitis RJ: Critically Selected Stability Constants of Metal Complexes. NTIS Database. Version 3.0. Gaithersburg, US Dept of Commerce, 1997.

26 Beal MF: Neurochemistry and toxin models in Huntington's disease. Curr Opin Neurol 1994;7:542-547.

27 Sheline CT, Behrens MM, Choi DW: Zincinduced cortical neuronal death: contribution of energy failure attributable to loss of $\mathrm{NAD}(+)$ and inhibition of glycolysis. J Neurosci 2000;20:3139-3146.

28 Stack EC, Matson WR, Ferrante RJ: Evidence of oxidant damage in Huntington's disease: translational strategies using antioxidants. Ann NY Acad Sci 2008;1147:79-92.

29 Zhou C, Huang Y, Przedborski S: Oxidative stress in Parkinson's disease: a mechanism of pathogenic and therapeutic significance. Ann NY Acad Sci 2008;1147:93-104.

30 Browne SE: Mitochondria and Huntington's disease pathogenesis: insight from genetic and chemical models. Ann N Y Acad Sci 2008;1147:358-382.

31 Gibson GE, Starkov A, Blass JP, Ratan RR, Beal MF: Cause and consequence: mitochondrial dysfunction initiates and propagates neuronal dysfunction, neuronal death and behavioral abnormalities in age-associated neurodegenerative diseases. Biochim Biophys Acta 1802:122-134.

32 Yang L, Calingasan NY, Wille EJ, Cormier K, Smith K, Ferrante RJ, Beal MF: Combination therapy with coenzyme Q10 and creatine produces additive neuroprotective effects in models of Parkinson's and Huntington's diseases. J Neurochem 2009;109:1427-1439.

33 Rosenstock TR, Duarte AI, Rego AC: Mitochondrial-associated metabolic changes and neurodegeneration in Huntington's disease - from clinical features to the bench. Curr Drug Targets 2010;11:1218-1236.

34 Zeviani M, Carelli V: Mitochondrial disorders. Curr Opin Neurol 2007;20:564-571.

- 35 Palacino JJ, Sagi D, Goldberg MS, Krauss S, Motz C, Wacker M, Klose J, Shen J. Mitochondrial dysfunction and oxidative damage in parkin-deficient mice. J Biol Chem 2004;279:18614-18622.

36 Schulz JB, Henshaw DR, Matthews RT, Beal MF: Coenzyme Q10 and nicotinamide and a free radical spin trap protect against MPTP neurotoxicity. Exp Neurol 1995;132:279283.

37 Sugino T, Nozaki K, Tokime T, Hashimoto N, Kikuchi H: 3-nitropropionic acid induces poly(ADP-ribosyl)ation and apoptosis related gene expression in the striatum in vivo. Neurosci Lett 1997;237:121-124.

38 Cosi C, Marien M: Implication of poly (ADPribose) polymerase (PARP) in neurodegeneration and brain energy metabolism. Decreases in mouse brain NAD+ and ATP caused by MPTP are prevented by the PARP inhibitor benzamide. Ann N Y Acad Sci 1999;890:227-239.

- 39 Mandir AS, Przedborski S, Jackson-Lewis V, Wang ZQ, Simbulan-Rosenthal CM, Smulson ME, Hoffman BE, Guastella DB, Dawson VL, Dawson TM: Poly(ADP-ribose) polymerase activation mediates 1-methyl-4-phenyl-1, 2,3,6-tetrahydropyridine (MPTP)-induced parkinsonism. Proc Natl Acad Sci USA 1999;96:5774-5779.

40 Bedalov A, Simon JA: Neuroscience. NAD to the rescue. Science 2004;305:954-955.

41 Hasbani DM, O'Malley KL: Wld(S) mice are protected against the parkinsonian mimetic MPTP. Exp Neurol 2006;202:93-99.

42 Press C, Milbrandt J: Nmnat delays axonal degeneration caused by mitochondrial and oxidative stress. J Neurosci 2008;28:48614871.

43 Cole TB, Wenzel HJ, Kafer KE, Schwartzkroin PA, Palmiter RD: Elimination of zinc from synaptic vesicles in the intact mouse brain by disruption of the ZnT3 gene. Proc Natl Acad Sci USA 1999;96:1716-1721.

44 Erickson JC, Hollopeter G, Thomas SA, Froelick GJ, Palmiter RD: Disruption of the metallothionein-III gene in mice: analysis of brain zinc, behavior, and neuron vulnerability to metals, aging, and seizures. J Neurosci 1997;17:1271-1281.

45 Mazzio EA, Reams RR, Soliman KF: The role of oxidative stress, impaired glycolysis and mitochondrial respiratory redox failure in the cytotoxic effects of 6-hydroxydopamine in vitro. Brain Res 2004;1004:2944.

46 Mazzio E, Soliman KF: The role of glycolysis and gluconeogenesis in the cytoprotection of neuroblastoma cells against 1-methyl 4-phenylpyridinium ion toxicity. Neurotoxicology 2003;24:137-147.

47 Mazzio E, Soliman KF: Pyruvic acid cytoprotection against 1-methyl-4-phenylpyridinium, 6-hydroxydopamine and hydrogen peroxide toxicities in vitro. Neurosci Lett 2003;337:77-80.

48 Holleman MAF: Notice sur l'action de l'eau oxygénée sur les acides $\alpha$-cétoniques et sur les dicétones 1.2. Recl Trav Chim Pays Bas 1904;23:169-171.

49 Sheline CT, Choi EH, Kim-Han JS, Dugan LL, Choi DW: Cofactors of mitochondrial enzymes attenuate copper-induced death in vitro and in vivo. Ann Neurol 2002;52:195204.

50 Sheline CT, Choi DW: Cu2+ toxicity inhibition of mitochondrial dehydrogenases in vitro and in vivo. Ann Neurol 2004;55:645653

51 Sheline CT, Cai AL: Compounds which maintain the NAD+/NADH ratio attenuated neuronal death induced by MPP+, 6-hydroxydopamine, and 3-nitopropionic acid in vitro and in vivo. New Orleans, Society for Neuroscience, Online, 2003, abstract viewer/ itinerary planner. 